\title{
FARINHA INTEGRAL DE TRIGO GERMINADO. 3. CARACTERÍSTICAS NUTRICIONAIS E ESTABILIDADE AO ARMAZENAMENTO${ }^{1}$
}

\author{
Martha Zavariz de MIRANDA ${ }^{2, *}$, Ahmed EL-DASH ${ }^{3}$
}

\begin{abstract}
RESUMO
O trigo (Triticum aestivum L.) é usado principalmente para alimentação humana, na forma de farinhas. A germinação pode ser útil para melhorar a qualidade protéica, bem como a de outros nutrientes do trigo, e a estabilidade das farinhas produzidas de trigo germinado é desconhecida. Assim, este trabalho investigou, em laboratório, o efeito da germinação sobre algumas características nutricionais e sobre a estabilidade ao armazenamento de farinhas integrais de trigo germinado por 48 (FITG48), 72 (FITG72) e 96 horas (FITG96). O perfil de aminoácidos das FITGs foi considerado bom, quando comparado com o da farinha controle e com o do padrão teórico da FAO para pré-escolares (2-5 anos). Somente a lisina (primeiro aminoácido limitante) e a treonina das FITGs mostraram valores mais baixos que o do citado padrão. O escore químico (em torno de 56-57) e o escore de aminoácidos corrigido pela digestibilidade protéica (em torno de 54-58) foram mais altos nas FITGs que na farinha integral controle ( 48 e 42 , respectivamente). Com base nesses resultados, as características nutricionais das FITGs foram melhoradas pela germinação de trigo. Com relação à estabilidade ao armazenamento, o pH diminuiu e a acidez álcool-solúvel aumentou de acordo com o tempo de germinação de trigo. As FITGs foram estáveis até 4 meses de armazenamento, com exceção da FITG96, que apresentou alto nível de acidez álcool-solúvel, provavelmente devido à rancidez hidrolítica. O hexanal, uma medida da deterioração oxidativa, foi encontrado somente na farinha controle; nas FITGs não foi detectado, indicando boa estabilidade oxidativa durante 6 meses de armazenamento.
\end{abstract}

Palavras-chave: farinha integral; germinação; nutrição; armazenamento.

\section{SUMMARY}

WHOLE FLOUR OF GERMINATED WHEAT. 3. NUTRITIONAL CHARACTERISTICS AND STORAGE STABILITY. Wheat (Triticum aestivum L.) is used mainly as human food in the form of flour. Germination may be useful to improve the quality of protein, and possibly other nutrients in wheat. Since the stability of flours produced from germinated grains is little known, this work investigated the effect of wheat germination on some nutritional characteristics and storage stability of whole wheat flour from grain germinated for 48 (WFGW48), 72 (WFGW72), and 96 hours (WFGW96). The amino acid profiles of the WFGWs were considered good when compared with the control whole flour and the FAO standard for pre-school-aged children (2-5y). Only lysine (first limiting amino acid) and threonine were lower in the WFGWs than in the reported standard. Chemical score (about 56-57) and protein digestibility-corrected amino acid score (about 54-58) were higher in the WFGWs than in the control whole flour ( 48 and 42 , respectively). Upon storage, the $\mathrm{pH}$ was observed to decrease and water-soluble acidity to increase as a function of germination time. WFGWs were stable up to 4 months of storage, except for WFGW96, which showed high water-soluble acidity probably due to hydrolitic rancidity. Hexanal, a measure of oxidative deterioration, was found only in the control whole flour; it was not detected in the WFGWs, indicating a good oxidative stability during 6 months of storage. On the basis of such results, germination improved both nutritionally and the storage stability of wheat.

Keywords: Whole wheat flour; germination; nutrition; storage.

\section{1 - INTRODUÇÃO}

Em vista da deficiência geral de alimentos com elevada qualidade protéica, qualquer procedimento que possa melhorar o valor nutricional de suprimentos alimentares imediatamente disponíveis (por exemplo, qualquer tipo de grão de cereal) pode ser interessante.

Uma das maneiras mais simples e efetivas para melhorar o valor nutricional do trigo é através do aumento da taxa de extração e/ou uso de farinha de trigo integral [4]. Algumas tecnologias de processamento de alimentos, como a preparação de concentrados protéicos, cozimento, germinação, maltagem e fermentação, também podem ser alternativas para elevar a qualidade nutricional de fontes vegetais.

1. Recebido para publicação em 04/08/1999. Aceito para publicação em 08/03/2002.

2. EMBRAPA Trigo, Rodovia BR 285, km 174, Cx. Postal 451, CEP 99001-970 Passo Fundo, RS. Fone: (54) 311-3444 E-mail: marthaz@cnpt.embrapa.br.

3. UNICAMP, FEA, Depto. de Tecnologia de Alimentos-Cx. Postal 6121, CEP 13083-970, Campinas, SP. Fone: (19) 3788-3997. E-mail: ahmed@fea.unicamp.br.

* A quem a correspondência deve ser enviada.
A germinação, possivelmente, é um dos processos mais antigos, simples e econômicos empregados para melhorar o valor nutricional de grãos de cereais e de leguminosas [17]. É uma alternativa adequada para diminuição de fatores antinutricionais, como os fitatos, inibidores da protease e taninos, presentes originalmente nestes grãos. Além de converter proteínas vegetais de baixa qualidade nutricional em proteínas de melhor qualidade, também provoca mudanças na composição centesimal, aumento nos teores de certos aminoácidos essenciais e vitaminas do complexo B, degradação parcial de proteínas e amido e melhora na digestibilidade [6].

Durante a germinação aumenta o teor de lipases, que agem sobre os lipídios causando rancidez hidrolítica. Do mesmo modo, as farinhas armazenadas por longo período aumentam a acidez [15], logo, o valor de acidez pode ser usado como uma medida objetiva da qualidade de um produto cereal. Outro tipo de deterioração que freqüentemente ocorre durante o armazenamento é a oxidação lipídica, que pode ser determinada pelo teor de hexanal, uma ferramenta útil para medir essa deterioração [10].

Existe vasta literatura internacional sobre germinação, destacando-se as revisões de LORENZ [20] e 
CHAVAN \& KADAN [7], contudo no Brasil poucos trabalhos sobre trigo germinado foram publicados [19, 27] e não foram encontrados relatos sobre características nutricionais e sobre estabilidade ao armazenamento de farinha integral obtida a partir de trigo germinado.

O objetivo deste trabalho foi avaliar o efeito do tempo de germinação de trigo em algumas características nutricionais e na estabilidade ao armazenamento de farinha integral.

\section{2 - MATERIAL E MÉTODOS}

\section{1 - Material}

Foi usado trigo nacional (Triticum aestivum L.), cultivar EMBRAPA 16. O teste de germinação apresentou $94,5 \%$ de sementes viáveis. O processo de produção de farinha integral de trigo germinado (FITG) seguiu as seguintes etapas: imersão de grãos de trigo em solução de hipoclorito de sódio a $1 \%(\mathrm{v} / \mathrm{v})$; lavagem com excesso de água; maceração; germinação do trigo por 48, 72 e 96 horas; secagem e moagem (moinho de martelos e, após, moinho de rolos). Com fins experimentais e visando ao aproveitamento integral, os grãos de trigo germinados foram moídos sem a retirada do coleóptilo e de radículas e as farinhas usadas integralmente.

Conforme dados já publicados, a composição química das farinhas integral controle, FITG48, FITG72 e FITG96, em base seca, foi a seguinte: 10,04, 10,70, 10,83 e $11,02 \%$ de proteina, $1,39,1,49,1,49$ e $1,50 \%$ de cinza, $2,10,2,15,2,13$ e $2,02 \%$ de lipídios e $86,47,85,66,85,55$ e $85,46 \%$ de carboidratos, respectivamente [22].

\section{2 - Métodos analíticos}

\subsection{1 - Análise de aminoácidos}

O perfil de aminoácidos (aa) foi determinado após hidrólise ácida das amostras com $\mathrm{HCl} 6 \mathrm{~N}$, por 22 horas a $110^{\circ} \mathrm{C}$, em ampolas seladas a vácuo. A proporção proteína: $\mathrm{HCl}$ foi de $5 \mathrm{mg}: 1 \mathrm{~mL}$. Os hidrolisados foram evaporados em dessecador contendo pastilhas de $\mathrm{NaOH}$ e, posteriormente, ressuspensos em tampão citrato $\mathrm{pH} 2,2$ (Na-S, Beckman Instr., Palo Alto, CA). Os aminoácidos sulfurados foram oxidados com ácido perfórmico e, então, hidrolisados com $\mathrm{HCl} 6 \mathrm{~N}$, seguindo procedimento descrito acima. A análise foi realizada por cromatografia de troca iônica com detecção pós-coluna de ninidrina em auto-analisador de aminoácidos Beckman, modelo 7300 , equipado com coluna de $200 \mathrm{~mm}$ de comprimento, contendo resina de troca iônica de sódio e operando em condições para hidrolisados protéicos. O teor de triptofano não foi determinado. O cálculo baseou-se no teor de proteina de cada farinha (item 2.1.) e os resultados foram expressos em $\mathrm{g}$ aa/100g proteína.

\subsection{2 - Lisina disponivel}

Foi analisada pelo procedimento de KAKADE \& LIENER [16], que determina o teor de lisina biologicamente ativa. O método baseia-se na reação dos grupos $\varepsilon$-amino livres da proteína com o TNBS 0,1\% (ácido 2,4,6trinitrobenzenosulfônico), que tem especificidade de reação com grupos amino primários, resultando em um trinitrofenil (TNP)-derivado de coloração amarela, que é determinado espectrofotometricamente a $346 \mathrm{~nm}$. O teor de lisina disponivel foi calculado aplicando-se a equação de Lambert-Beer, e os resultados expressos em g Lys disponivel / 100g de proteina.

\subsection{3 - Digestibilidade protéica in vitro}

Foi determinada pelo método de AKESON \& STAHMANN [1] com pequenas modificações. A amostra foi digerida com pepsina a $37^{\circ} \mathrm{C}$ por 3 horas, após com pancreatina por 24 horas, quando foi interrompida com TCA (ácido tricloroacético) a 30\%. A porcentagem de digestibilidade da proteína foi calculada como a relação entre o nitrogênio hidrolisado e o conteúdo de nitrogênio da amostra testada (obtidos por microKjeldahl), usando o fator 5,7 .

\subsection{4 - Escore químico}

Foi calculado a partir da determinação de aminoácidos (aa) pela divisão dos teores de cada um dos aminoácidos essenciais da proteína em estudo pelo aminoácido correspondente do padrão de referência da FAO/WHO/ UNU [8] para crianças de 2-5 anos (foi transformado de mg de aa/g proteína para g aa/100g de proteína). O aminoácido para o qual a proteína apresentou o escore mais baixo foi o aminoácido limitante e tornou-se o escore químico.

\subsection{5 - Escore de aminoácidos corrigido pela digestibilidade protéica (PDCAAS)}

Foi calculado em porcentagem, conforme PETZKE et al. [26], multiplicando-se o escore químico (EQ) do aminoácido limitante pela digestibilidade in vitro e dividindo o resultado por 100 .

\subsection{6 - pH}

Foi determinado nos tempos de armazenamento de 0, 2, 4 e 6 meses, pelo método potenciométrico para determinação de $\mathrm{pH}$ de farinha, AOAC - método 943.02 [3].

\subsection{7 - Acidez álcool-solúvel}

Foi empregado o método da acidez (álcool a 95\%) para farinha, segundo NORMAS ANALÍTICAS DO INSTITUTO ADOLFO LUTZ [25], com detecção pela viragem do $\mathrm{pH}$ para 8,3 (fenolftaleína), segundo MOLTEBERG et al. [24]. Os resultados foram expressos em $\mathrm{mL}$ de solução $\mathrm{N} \%$ v/p. Foi determinada nos tempos de 0, 2, 4 e 6 meses.

\subsection{8 - Hexanal}

Seguiu o procedimento de FRITSCH \& GALE [10], com algumas adaptações. A concentração de hexanal nas farinhas foi determinada pela adição de $150 \mathrm{~mL}$ de água fervente a 15 gramas de amostra adicionada de $500 \mu \mathrm{L}$ de padrão interno (contendo $0,1 \mu \mathrm{L}$ de 4-heptanona) em Erlenmeyer hermeticamente fechado, com agita- 
ção intermitente por 45 segundos; a seguir, foi injetado $1 \mathrm{~mL}$ de "headspace" com seringa de ar, em cromatógrafo gasoso Varian 3400, com detector de ionização de chama. O tempo de corrida foi de 20 minutos. As condições usadas no cromatógrafo foram: coluna empacotada de aço inoxidável 4\%OV101 / 6\%OV210 CWHP (80 a $100 \mathrm{mesh}$ ), medindo $2,0 \mathrm{~m}$ de comprimento x $1 / 8$ " de diâmetro; injetor tipo "on column"; atenuação de $2 \times 10^{-10}$; temperaturas de $100^{\circ} \mathrm{C}$ da coluna, $150^{\circ} \mathrm{C}$ do injetor, $150^{\circ} \mathrm{C}$ do auxiliar (FID) e $50^{\circ} \mathrm{C}$ do detector. A proporção dos gases usados foi de 1:1:10 (hidrogênio:nitrogênio:ar sintético). As áreas dos picos foram quantificadas pelo integrador Varian 4400. A curva de calibração foi construida com quantidades crescentes de hexanal (pureza 99\%) em etanol e realizada nas mesmas condições de teste. O valor da relação entre a área do pico de hexanal padrão e a área do pico de padrão interno (y) foi plotado contra a concentração de hexanal (x), obtendo-se a seguinte equação da reta: $\mathrm{y}=-5,6717+1,13692 . \mathrm{x}$ $(\mathrm{R}=0,99863)$. A mesma relação foi usada para o cálculo da concentração de hexanal das amostras ( $\mu \mathrm{g} / \mathrm{g}$ ). O hexanal foi determinado nos tempos de armazenamento de 0,3 e 6 meses.

\section{3 - Análise estatística}

Foi realizada com o programa SAS for Windows, submetendo os resultados experimentais à análise de variância (ANOVA) e ao teste de Tukey, ao nivel de 5\% de probabilidade [28].

\section{3 - RESULTADOS E DISCUSSÃO}

O valor nutritivo de uma proteina depende, sobretudo, de sua capacidade de fornecer aminoácidos, em quantidades adequadas, para suprir as necessidades do organismo. Assim, em teoria, a maneira mais lógica para avaliar a qualidade protéica é comparar o conteúdo de aminoácidos de um alimento com as necessidades humanas, através do escore químico [5].

Na Tabela 1 está apresentada a composição em aminoácidos e escore químico das proteínas de farinhas integrais de trigo germinado (FITGs) e perfil de aminoácidos essenciais para uma proteina ideal, segundo recomendações da FAO/WHO/UNU [8] para pré-escolares de 2 a 5 anos de idade. A composição em aminoácidos, expressa em g de aminoácidos / $100 \mathrm{~g}$ de proteína de cada FITG, apresentou recuperação superior a 97\%, sendo recalculada para $100 \%$ para facilitar a comparação dos resultados entre os perfís de aminoácidos de cada farinha.

Na mesma tabela, pode-se observar que os aminoácidos com grupos carboxilicos livres (Glu e Asp), estão presentes em quantidades substanciais no trigo, e embora o teor de ácido glutâmico tenha diminuído de aproximadamente $31 \%$ na farinha controle para $27 \%$ nas FITGs (média), o teor de ácido aspártico aumentou significativamente com o aumento do tempo de germinação (de 5,67\% na farinha integral controle para $7,45 \%$, em média, nas FITGs). Os aminoácidos com cadeias hidrofóbicas (Ala,
Gly, Ile, Leu, Met, Pro e Val) estão presentes em cerca de $35,7 \%$ na farinha controle e $36,56 \%$ nas FITGs (média); enquanto os hidrofilicos (Ser, Cistina e Thr) em 11,97\% na farinha controle e $11,61 \%$ nas FITGs (média). Os aminoácidos básicos totais (Lys, His e Arg) estão presentes em torno de 9,21\% na farinha controle e 10,12\% nas FITG e os aminoácidos aromáticos (Phe e Tyr) em 6,33\% na farinha controle e 6,57\% nas FITGs (média).

A tirosina foi o aminoácido encontrado em menor e o ácido glutâmico em maior quantidade, nas FITGs, embora os teorres deste último juntamente com os da serina, tenham diminuído significativamente com a germinação de trigo. Durante a germinação ocorre hidrólise das prolaminas e aminoácidos como ácido glutâmico são convertidos em lisina [14]. O trigo germinado possui valor nutricional aumentado, porém suas características tecnológicas são prejudicadas, isto ocorre em conseqüência da diminuição do teor de gliadina (prolamina) e glutenina (glutelina), que são as proteínas formadoras do glúten e ao aumento das albuminas e globulinas, que não formam massa, mas são ricas em lisina.

TABELA 1. Composição em aminoácidos e escore químico das proteinas de farinhas integrais de trigo germinado (FITGs) e perfil de aminoácidos essenciais para uma proteína ideal, segundo recomendações da $\mathrm{FAO} / \mathrm{WHO} / \mathrm{UNU}$ [8] para préescolares de 2 a 5 anos de idade.

\begin{tabular}{|c|c|c|c|c|c|}
\hline \multirow[b]{2}{*}{ AMINOÁCIDO } & \multicolumn{4}{|c|}{ AMINOÁCIDO (g aa / $100 \mathrm{~g}$ proteina* $)^{1}$} & \multirow{2}{*}{$\begin{array}{c}\text { PADRÃO } \\
\text { FAO } \\
(\mathrm{g} / \mathbf{1 0 0 g})\end{array}$} \\
\hline & FIT Controle & FTT G48 & FITG72 & FITG96 & \\
\hline Ádido aspártico (Asp) & $5,67 \pm 0,11^{c}$ & $6,94 \pm 0,27^{b}$ & $7,60 \pm 1,35^{\text {a }}$ & $7,81 \pm 0,41^{a}$ & - \\
\hline Treonina (Thr) & $3,27 \pm 0,10^{\text {ns }}$ & $3,33 \pm 0,13^{\text {ns }}$ & $3,38 \pm 0,59^{\text {ns }}$ & $3,26 \pm 0,10^{\mathrm{ns}}$ & 3,4 \\
\hline Serina (Ser) & $4,60 \pm 0,19^{a}$ & $4,37 \pm 0,19^{b}$ & $4,38 \pm 0,80^{\mathrm{b}}$ & $4,28 \pm 0,09^{\mathrm{b}}$ & - \\
\hline Ádido glutâmico (Gu) & $31,10 \pm 0,29^{\text {a }}$ & $28,46 \pm 1,06^{b}$ & $27,77 \pm 4,93^{b}$ & $26,77 \pm 0,86^{\mathrm{c}}$ & - \\
\hline Prolina (Pro) & $10,61 \pm 0,10^{\mathrm{ns}}$ & $10,77 \pm 0,42^{\mathrm{ns}}$ & $10,74 \pm 1,93^{\mathrm{ns}}$ & $10,86 \pm 0,36^{\mathrm{ns}}$ & - \\
\hline Gicina (Gy) & $4,27 \pm 0,13^{\mathrm{ns}}$ & $4,24 \pm 0,23^{\mathrm{ns}}$ & $4,22 \pm 0,74^{\mathrm{ns}}$ & $4,19 \pm 0,16^{\text {ns }}$ & - \\
\hline Alanina (Ala) & $3,66 \pm 0,12^{\mathrm{b}}$ & $3,95 \pm 0,19^{\mathrm{a}}$ & $4,10 \pm 0,73^{\mathrm{a}}$ & $4,08 \pm 0,12^{\mathrm{a}}$ & - \\
\hline Gistina & $4,10 \pm 0,02^{\text {ns }}$ & $4,03 \pm 0,07^{\mathrm{ns}}$ & $3,83 \pm 0,07^{\text {ns }}$ & $3,98 \pm 0,14^{\mathrm{ns}}$ & _ \\
\hline Valina (Val) & $4,43 \pm 0,07^{\mathrm{b}}$ & $4,72 \pm 0,10^{\mathrm{a}}$ & $4,81 \pm 0,99^{\mathrm{a}}$ & $4,76 \pm 0,05^{\mathrm{a}}$ & 3,5 \\
\hline Metionina (Met) & $2,30 \pm 0,00^{\mathrm{ns}}$ & $2,16 \pm 0,06^{\mathrm{ns}}$ & $2,06 \pm 0,04^{\mathrm{ns}}$ & $2,16 \pm 0,08$ ns & - \\
\hline Isoleı ina (Ile) & $3,49 \pm 0,05^{\mathrm{ns}}$ & $3,75 \pm 0,12^{\mathrm{ns}}$ & $3,79 \pm 0,89^{\mathrm{ns}}$ & $3,70 \pm 0,12$ ns & 2,8 \\
\hline Leucina (Leu) & $6,94 \pm 0,12^{\mathrm{ns}}$ & $6,91 \pm 0,11^{\mathrm{ns}}$ & $6,92 \pm 1,40^{\mathrm{ns}}$ & $6,78 \pm 0,02^{\text {ns }}$ & 6,6 \\
\hline Tirosina (Tyr) & $1,73 \pm 0,06^{\mathrm{ns}}$ & $1,87 \pm 0,222^{\text {ns }}$ & $1,89 \pm 0,50^{\mathrm{ns}}$ & $1,86 \pm 0,18^{\text {ns }}$ & - \\
\hline Fenilalanina (Phe) & $4,60 \pm 0,06^{\mathrm{ns}}$ & $4,69 \pm 0,03^{\mathrm{ns}}$ & $4,73 \pm 0,96^{\mathrm{ns}}$ & $4,67 \pm 0,02^{\mathrm{ns}}$ & - \\
\hline His tidina (His) & $2,46 \pm 0,05^{\mathrm{ns}}$ & $2,47 \pm 0,11^{\mathrm{ns}}$ & $2,32 \pm 0,42^{\mathrm{ns}}$ & $2,30 \pm 0,07^{\mathrm{ns}}$ & 1,9 \\
\hline Lisina (Lys) & $2,77 \pm 0,10^{\mathrm{b}}$ & $3,24 \pm 0,17^{\mathrm{a}}$ & $3,30 \pm 0,58^{a}$ & $3,28 \pm 0,06^{\mathrm{a}}$ & 5.8 \\
\hline Trip tofano (Trp) & N.A. & N.A. & N.A. & N.A. & 1,1 \\
\hline Arginina (Arg) & $3,98 \pm 0,10^{\mathrm{ns}}$ & $4,09 \pm 0,06^{\mathrm{ns}}$ & $4,16 \pm 0,64^{\mathrm{ns}}$ & $5,25 \pm 0,98^{\mathrm{ns}}$ & - \\
\hline TOTAL & $100 \%$ & $100 \%$ & $100 \%$ & $100 \%$ & - \\
\hline Metionina + Cistina & 6,40 & 6,19 & 5,89 & 6,14 & 2,5 \\
\hline $\begin{array}{l}\text { Fenilalanina }+ \\
\text { Tirosina }\end{array}$ & 6,28 & 6,56 & 6,62 & 6,53 & 6,3 \\
\hline $\begin{array}{l}\text { ESCORE } \\
\text { QUíMICO*** }\end{array}$ & 48 & 56 & 57 & 57 & - \\
\hline
\end{tabular}

* proteina = N x 5,7; NA =não analisado; Resultados expressos em base seca. ** Padrão FAO/WHO/UNU (1985) para pré-escolares de 2 a 5 anos de idade: proteí$\mathrm{na}=\mathrm{N} \mathrm{x} 6,25$ (transformado de $\mathrm{mg}$ aa/g de proteína para g aa/ $100 \mathrm{~g}$ proteína).
$* * *$ Escore quimico $(\mathrm{EQ})=(\mathrm{g}$ aa/ $100 \mathrm{~g}$ prot.)/Padrão FAO x $100=\mathrm{EQ}$ do aminoâcido $* * *$
limitante, neste caso a lisina.

Resultados da composição em aminoácidos representam a média de 3 determinações \pm desvio padrão.

${ }^{1}$ Letras diferentes, nas linhas, diferem estatisticamente pelo Teste de Tukey $(\mathrm{p} \leq 0,05)$.

O teor dos aminoácidos ácido aspártico, alanina, valina e lisina aumentou significativamente nas FITGs em relação à farinha integral controle. Os demais aminoácidos (Thr, Pro, Gly, cistina, Met, Ile, Leu, Tyr, Phe, 
His e Arg) não sofreram alterações significativas pelo teste de Tukey ( $p \leq 0,05)$. Na Figura 1 pode-se observar os aminoácidos das FITGs que sofreram alterações significativas em conseqüência do processo de germinação.

TKACHUK [30] encontrou o ácido glutâmico como o aminoácido presente em maior quantidade e a cistina em menor, em amostras de trigo germinado por 48 e 72 horas. Os demais aminoácidos todos aumentaram em relação ao trigo sem germinar, sendo que os maiores aumentos foram nos teores de glutamina e prolina. Aumentos consideráveis também foram encontrados nos teores de Lys, Ala, Val, Leu, embora não tenha sido realizada análise estatística.

Com base nas necessidades de aminoácidos para humanos [8], foram calculados os aminoácidos limitantes e o escore de aminoácidos. Este último baseia-se nos 9 aminoácidos essenciais $\left(\mathrm{EAA}_{9}\right)$ para humanos (Hys, Ile, Leu, Lys, Met + Cistina, Phe + Tyr, Thr, Trp e Val).

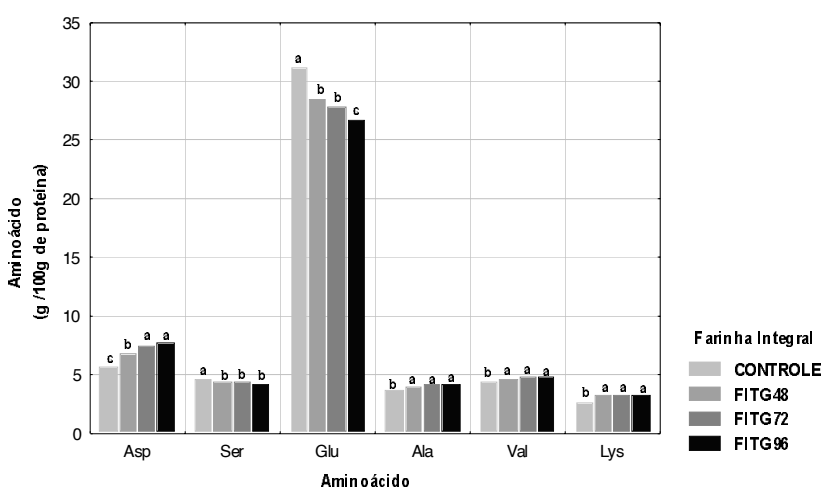

Letras minúsculas diferentes para cada aminoácido, diferem significativamente, pelo teste de Tukey $(\mathrm{p} \leq 0,05)$.

FIGURA 1. Aminoácidos das FITGs que sofreram alterações significativas em conseqüência do processo de germinação.

Da mesma forma que nos demais cereais, a lisina foi o primeiro aminoácido limitante, seguido pela treonina, em todas as amostras de FITGs. O teor de lisina aumentou significativamente nas FITGs (de 3,24 a 3,30g/100g) em relação da farinha integral controle $(2,77 \mathrm{~g} / 100 \mathrm{~g})$, porém não alcançou o valor recomendado pelo padrão da FAO $(5,8 g / 100 g)$. Com exceção da valina, que apresentou aumento significativo, os teores dos demais aminoácidos essenciais nas FITGs, embora sem aumentos significativos apresentaram-se superiores aos do referido padrão, indicando um balanço nutricional adequado da maioria dos aminoácidos essenciais, incluindo a combinação de metionina + cistina e fenilalanina + tirosina. As FITGs apresentaram escore químico em torno de 56-57, ou seja, superior ao verificado pela farinha controle, que foi 48 .

Na Tabela 2 encontram-se os indices de avaliação in vitro para as FITGs: teores de lisina total, lisina disponível, digestibilidade in vitro e o PDCAAS (escore de aminoácidos corrigido pela digestibilidade protéica, calculado pela digestibilidade in vitro).
TABELA 2. Teores de lisina total, lisina disponível, digestibilidade in vitro e escore de aminoácidos corrigido pela digestibilidade protéica (PDCAAS*) de FITGs.

\begin{tabular}{|c|c|c|c|c|c|}
\hline $\begin{array}{c}\text { FAR. INTEGRAL } \\
\text { DE TRIGO }\end{array}$ & $\begin{array}{c}\text { Lisina tota } \\
\text { (gL Lys/ } 100 \text { gproténa) }\end{array}$ & $\begin{array}{l}\text { Lisina disponível } \\
\text { (gLys 100gproténa) }\end{array}$ & $\begin{array}{l}\text { Disponibilid ade } \\
\text { de lisina (\%) }\end{array}$ & $\begin{array}{c}\text { Digestibilidade } \\
\text { in vitro (\%) }\end{array}$ & $\begin{array}{l}\text { PDCAAS ** } \\
\text { (\%) }\end{array}$ \\
\hline Controle & $2,77 \pm 0,10^{b}$ & $1,92 \pm 0,10^{b}$ & 69 & $88 \pm 2^{\text {n.s. }}$ & 42 \\
\hline Germ in alo $48 \mathrm{~h}$ & $3,24 \pm 0,17^{\mathrm{a}}$ & $4,05 \pm 0,11^{\mathrm{a}}$ & 125 & $97 \pm 6^{\text {ns. }}$ & 54 \\
\hline Germ in ado $72 \mathrm{~h}$ & $3,30 \pm 0,58^{\mathrm{a}}$ & $4,16 \pm 0,05^{\mathrm{a}}$ & $126 \bullet$ & $102 \pm 2^{\text {n.s. }}$ & 58 \\
\hline Germ in ado 96h & $3,28 \pm 0,06^{\mathrm{a}}$ & $4,09 \pm 0,02^{a}$ & 125 & $84 \pm 4^{\text {ns. }}$ & 56 \\
\hline
\end{tabular}

* PDCAAS $=(E Q$ do aa limitante $\mathrm{x}$ digestibilidade in vitro $) / 100$.

** PDCAAS= calculado pela digestibilidade in vitro.

- Valores superiores a $100 \%$.

(lisina total e lisina disponivel: 3 determinações; digestibilidade in vitro: 2 determinacões). Letras diferentes, nas colunas, diferem significativamente, pelo teste de Tukey

O teor de lisina, aminoácido essencial para o crescimento, é considerado um indicador do valor biológico da proteina, contudo, o teor de lisina total nem sempre correlaciona-se com o valor nutricional, porque parte dos grupos $\alpha$ e $\varepsilon$-amino livres das proteinas podem ter reagido com compostos naturais, como por exemplo, açúcares redutores em alimentos processados, ou aldeídos provenientes da autoxidação de gorduras durante o processamento ou a estocagem do produto. Desta forma, é muito importante a determinação do teor de lisina disponivel ou biologicamente ativa.

Não foram encontrados dados de literatura sobre disponibilidade de lisina em farinha obtida de trigo germinado. Contudo, TAVERNER \& FARREL [31, 32] encontraram para trigo valores de lisina disponivel na faixa de 0,79 a 0,94\%. CARPENTER et al. [6] encontraram para o grão de trigo 2,23 a 2,57g de lisina disponivel/ $16 \mathrm{~g}$ de $\mathrm{N}$ (100g de proteína).

O valor de lisina disponivel encontrado na farinha integral controle foi de 1,92g de lisina/100g de proteina; o que corresponde a $69 \%$ de lisina disponivel em relação à lisina total (Tabela 2). Contudo, foram obtidos valores superiores a $100 \%$ para a disponibilidade de lisina presente nas FITGs (de 125 a 126\%), em relação à lisina total. Uma possivel explicação para isso seria o fato de que a técnica empregada para determinar lisina disponível, usa o reagente TNBS (ácido trinitro benzeno sulfônico), não faz distinção entre os grupos $\varepsilon$-amino da lisina e os $\alpha$-amino dos aminoácidos $\mathrm{N}$-terminais, reagindo com ambos. Caso a extração dos derivados $\alpha$-amino com éter etílico não seja completa, estes podem ficar na fase aquosa juntamente com o derivado $\varepsilon$-lisina, sendo computados como derivado $\varepsilon$-lisina, resultando em altos valores de lisina disponivel e, conseqüentemente, em alta taxa de disponibilidade em relação à lisina total.

PETZKE et al. [26] também encontraram resultados de disponibilidade de lisina superestimados (de 115 a $233 \%$ ) em sementes da família das leguminosas, o que atribuíram a fatores da matriz da amostra relacionados aos constituintes carboidratos, que quando aquecidos com ácido clorídrico $(\mathrm{HCl})$, produzem furfural, que pode ser o agente redutor responsável pela perda de grupos $\varepsilon$ amino. 
A digestibilidade protéica determina a disponibilidade dos aminoácidos contidos nas proteínas alimentares [33]. A digestibilidade in vitro não apresentou diferenças significativas quando foram comparadas as farinhas integrais de trigo controle e FITGs (Tabela 2). Foi encontrado $88 \%$ de digestibilidade in vitro para a farinha integral controle, que está de acordo com dados relatados na literatura. Conforme o FOOD AND DRUG ADMINISTRATION [9], o valor para a digestibilidade verdadeira do grão de trigo é $87 \%$. MILADI et al. [21] obtiveram para o trigo integral $91 \%$ de digestibilidade in vitro, enquanto TAVERNER \& FARRELL [31] encontraram para trigos de diferentes variedades valores de digestibilidade in vitro na faixa de 80 a 91\%, e TAVERNER \& FARRELL [32], valores médios para o trigo de 92\%. WOLZAK et al. [33] compararam as estimativas de digestibilidade in vivo e in vitro de várias proteínas vegetais, obtendo para o trigo integral 81,6 e 90,7\%, respectivamente, e encontraram correlações altamente significativas entre os dois métodos.

Para melhorar a exatidão dos procedimentos de escore, o conteúdo de aminoácidos determinados quimicamente pode ser corrigido pela digestibilidade [5]. O escore de aminoácidos corrigido pela digestibilidade protéica (PDCAAS) é geralmente calculado usando-se valores de digestibilidade verdadeira. Contudo, BOUTRIF [5] sugere que procedimentos promissores de digestibilidade in vitro sejam aperfeiçoados e avaliados. PETZKE et al. [26] empregaram a digestibilidade protéica in vitro para esse cálculo, baseados em AKESON \& STAHMANN [1], que demonstraram ser análogos aos resultados obtidos por métodos in vivo aplicados em ratos. O PDCAAS da farinha integral controle obtido no presente trabalho foi $42 \%$, bem próximo do valor obtido por HENLEY \& KUSTER [13], que citam 0,40 ou 40\% para o PDCAAS da proteína do grão de trigo. O PDCAAS das FITGs (FITG48, FITG72 E FITG96) situou-se na faixa de 54-58\%, sendo superior ao da farinha integral controle.

O fenômeno de envelhecimento de farinhas de trigo está intimamente ligado aos lipídios e é extremamente complexo [12]. A farinha integral é muito suscetivel à deterioração por rancificação porque no processo de moagem dos grãos de trigo, o óleo e as enzimas presentes no germe são liberados, além disso a armazenagem da farinha é feita a temperatura ambiente.

Quanto à estabilidade ao armazenamento, JESSENHANSEN citado por JOHNSON \& GREEN [15], foi o primeiro a expressar o aumento da acidez de farinhas armazenadas em termos de concentração de íon hidrogênio de seus extratos e demonstrar que as farinhas aumentaram sua concentração em ion hidrogênio durante o armazenamento. De acordo com GRACZA [12], uma vez que a concentração do íon-hidrogênio está diretamente relacionada com as medidas de acidez titulável, dados de $\mathrm{pH}$ foram registrados em estudos de armazenagem. Concluiram que o $\mathrm{pH}$ da farinha de trigo diminui com o envelhecimento, de acordo com os niveis de mudança da acidez.

A variação do $\mathrm{pH}$ de acordo com o tempo de armaze- namento das FITGs é mostrada na Figura 2. Comparando as FITG48 até a FITG96, observa-se que o pH diminuiu com o aumento do tempo de germinação das farinhas integrais de trigo e com o tempo de armazenamento das farinhas. $\mathrm{O} \mathrm{pH}$ da farinha integral controle foi sempre maior que o das FITGs.

Resultados próximos ao da farinha controle foram encontrados por JOHNSON \& GREEN [15] em trigo moído ( $\mathrm{pH}$ de 6,39) e por SHARP [29] em trigo moído armazenado a $22^{\circ} \mathrm{C}$ por 0,4 e 8 meses, verificando $\mathrm{pH}$ de $6,40,6,36$ e 6,31, respectivamente.

LARSSON \& SANDBERG [18], em estudo sobre maltagem de aveia, observaram uma redução do $\mathrm{pH}$, que provavelmente resultou da produção de ácido láctico durante a maceração (16h) à temperatura ambiente e sugerem que isso explique o motivo das suspensões de aveia mostrarem-se resistentes à contaminação microbiana durante a maceração. JOHNSON \& GREEN [15] encontraram pequenas quantidades de ácido láctico em solução aquosa, concluindo que os ácidos graxos formados durante o armazenamento da farinha de trigo podem ser, isoladamente, responsáveis pelo aumento na concentração de íon hidrogênio que ocorreu durante o armazenamento.

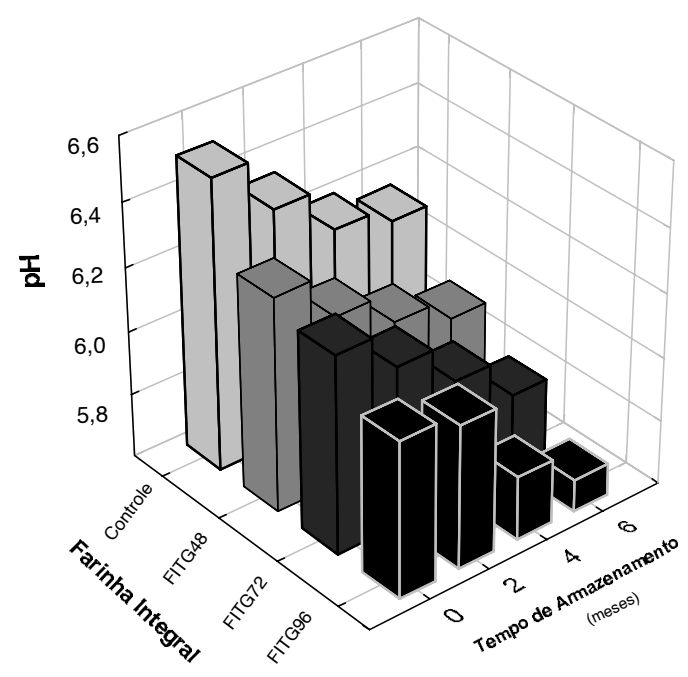

FIGURA 2. Variação do pH de acordo com o tempo de armazenamento das FITGs.

As farinhas armazenadas por longo periodo têm sua acidez aumentada. Isso tem sido atribuído à ocorrência de vários fenômenos diferentes: hidrólise gradual de lipídios, produzindo ácidos graxos; hidrólise de proteínas, produzindo aminoácidos ou produtos intermediários da decomposição de proteínas, e separação enzimática da fitina, produzindo ácido fosfórico [15]. A Figura 3 mostra a variação de acidez álcool-solúvel de acordo com o tempo de armazenamento das FITGs.

A Resolução 12/78 da Comissão Nacional de Normas e Padrões para Alimentos (CNNPA) indica um limite máximo de 4,0mL de solução $\mathrm{N} \% \mathrm{v} / \mathrm{p}$ para farinha integral [2]. Assim, até dois meses de armazenamento as 
farinhas atendem ao valor estipulado. Em 4 meses de armazenamento somente a FITG96 situou-se acima do limite, e em 6 meses de armazenamento a única farinha enquadrada dentro do limite foi a FITG48.

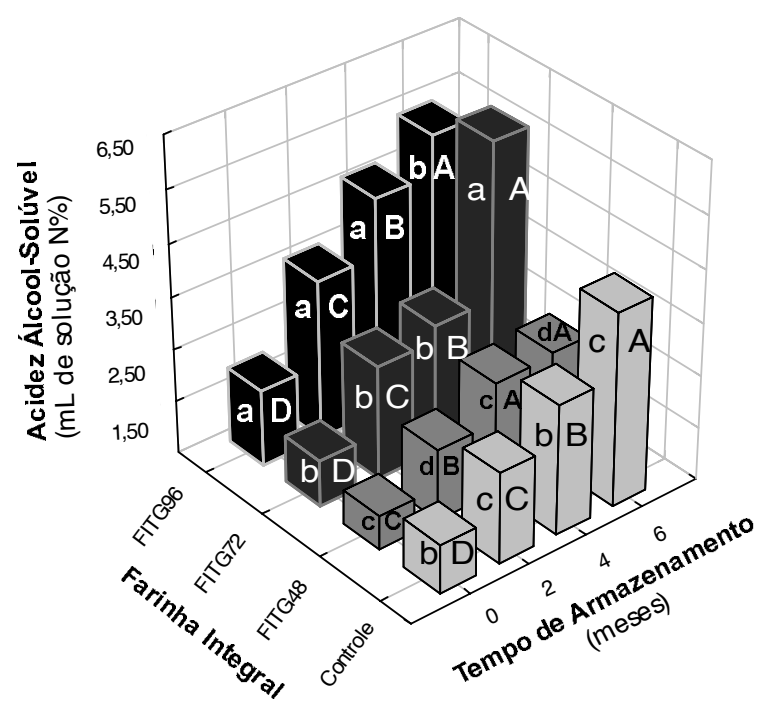

Letras maiúsculas diferentes, em colunas com tonalidades iguais, diferem significa-

tivamente, pelo teste de Tukey $(\mathrm{p} \leq 0,05)$.
Letras minúsculas diferentes, em colunas com tonalidades diferentes, na seqüência, diferem significativamente, pelo teste de Tukey $(\mathrm{p} \leq 0,05)$

FIGURA 3. Variação da acidez álcool-solúvel conforme o tempo de armazenamento das FITGs.

Em geral, a acidez álcool-solúvel aumentou da FITG48 até a FITG96 (Figura 3), o que está de acordo com o $\mathrm{pH}$ que diminuiu com o aumento do tempo de germinação de trigo (Figura 2). A acidez álcool-solúvel elevou-se significativamente em todas as farinhas com o aumento do tempo de armazenamento de trigo.

A FITG48 apresentou menor acidez álcool-solúvel e maior $\mathrm{pH}$ entre as FITGs, apresentando também o menor valor de lisina total. Trabalhos anteriores mostraram também que a FITG48 apresentou os menores valores de índices de absorção de água (IAA) e de solubilidade em água (ISA), fibra alimentar, minerais e açúcares e o maior conteúdo de fitato. Tudo isso parece ter contribuído para o comportamento diferenciado da FITG48 entre as demais FITG [22, 23].

Como indicador da oxidação lipídica, foi empregada a análise do hexanal por cromatografia gasosa, por ser um método especifico e sensivel. Também, porque para alimentos com baixos teores de lipídios a determinação de peróxidos, de ácido tiobarbitúrico e de "uptake" de oxigênio ou é difícil de aplicar ou estes não são sensiveis o suficiente [10]. A variação do teor de hexanal das amostras está apresentada na Figura 4.

O teor de hexanal da farinha integral controle aumentou significativamente após 3 e 6 meses de armazenamento ( $297 \%$ e $731 \%$, respectivamente), enquanto nas FITG48, FITG72 e FITG96 não foi detectado hexanal.

Em alimentos com baixo teor de lipídios, particularmente aqueles que contém quantidades substanciais de ácido linoléico, que segundo GALLIARD [11] corresponde a mais de $50 \%$ dos aminoácidos do trigo, e que possuem menos de $1 \mathrm{ppm}$ de hexanal quando novos, um aumento de $5 \mathrm{ppm}$ ou mais indica que houve uma significativa deterioração na qualidade, devido à oxidação lipídica [10].

Assim, a farinha integral controle, que apresentou $5,82 \mathrm{ppm}$ de hexanal com 6 meses de armazenamento, apresentou-se deteriorada para consumo. Além disso, nesse tempo de armazenamento foi perceptivel o odor de rancidez, enquanto as FITG permaneceram normais. As razões para isto não foram esclarecidas. Uma hipótese é o efeito protetor exercido por substâncias contidas no trigo germinado, que tenham ação antioxidante. Um grupo destas substâncias, os tocoferóis estão presentes em pequena quantidade no trigo germinado, enquanto que a vitamina $\mathrm{C}$ inexistente no trigo sem germinar, pode ser encontrada em baixos teores no trigo germinado. Contudo, são necessários mais estudos para esclarecer esta possibilidade.

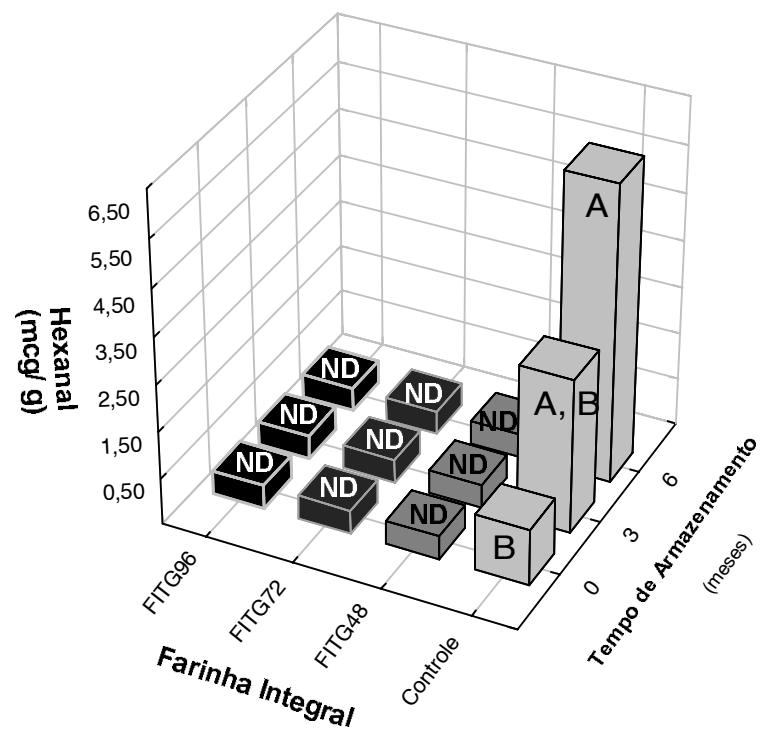

Letras maiúsculas diferentes, nas colunas com tonalidades iguais, diferem significativamente pelo teste de Tukey $(\mathrm{p} \leq 0,05)$.

FIGURA 4. Variação dos teores de hexanal conforme o tempo de armazenamento das FITGs.

\section{4 - CONCLUSÕES}

A partir dos resultados obtidos no presente trabalho foi possivel concluir que as FITGs podem representar uma opção para alimentação humana pois apresentam características nutricionais desejáveis e boa estabilidade ao armazenamento.

- A composição em aminoácidos das FITGs mostrou-se semelhante aos demais cereais, quanto aos aminoácidos limitantes, que foram a lisina e a treonina, sendo que para os demais aminoá- 
cidos superou o padrão teórico da FAO para préescolares de 2-5 anos;

- As características nutricionais das FITGs, foram melhoradas pela germinação de trigo, como demonstrado pelos valores significativamente superiores dos aminoácidos ácido aspártico, valina, alanina e lisina; pelo maior valor de escore químico (em torno de 56-57) e escore de aminoácidos corrigido pela digestibilidade protéica (em torno de 54-58), em relação à farinha controle (48 e 42, respectivamente);

- As FITGs foram estáveis ao armazenamento por 4 meses, com exceção da FITG96, que apresentou alto nivel de acidez álcool-solúvel. O hexanal não foi detectado nas FITGs durante os 6 meses de armazenamento, indicando boa estabilidade oxidativa;

- O teor de hexanal das FITGs, durante o armazenamento por 3 e 6 meses correlacionou-se positivamente com os teores de lisina total e de lisina disponivel ( $\mathrm{r}=1,00)$, e também com o PDCAAS $(\mathrm{r}=0,97)$.

\section{5 - REFERÊNCIAS BIBLIOGRÁFICAS}

[1] AKESON, W.R.; STAHMANN, M.A. A pepsin pancreatin digested index of protein quality evaluation. Journal of Nutrition, v. 83, n. 3, p. 257-261, 1964.

[2] ASSOCIAÇÃO BRASILEIRA DAS INDÚSTRIAS DE ALIMENTAÇÃO. Compêndio da Legislação de Alimentos. São Paulo: ABIA, 1992.

[3] ASSOCIATION OF OFFICIAL AGRICULTURAL CHEMISTS (Arlington, VI, USA). Methods of Analysis of AOAC International. 16 ed. Arlington, 1995. v. 2, cap. 32, p. 1-43.

[4] BETSCHART, A.A. Nutritional quality of wheat and wheat products. In: POMERANZ, Y. Wheat: chemistry and technology. 3 ed. Saint Paul: A.A.C.C., 1988. v. 2: p. 91129.

[5] BOUTRIF, E. Recent developments in protein quality evaluation. Food Nutrition and Agriculture/ Alimentation Nutrition et Agriculture, Rome, v. 2/3, p. 36-4, Dec. 1991.

[6] CARPENTER, K.J.; STEINKE, F.H.; CATIGNANI, G.L. et al. The estimation of 'available lisine' in human foods by three chemical procedures. Plant Foods for Human Nutrition, v. 39, n. 1, p. 129-135, 1989.

[7] CHAVAN, J.K.; KADAN, S.S. Nutritional improvement of cereals by sprouting. Critical Reviews in Food Science and Technology, v. 28, n. 5, p. 401-437, 1989.

[8] FAO/WHO/UNU expert consultation. Energy and protein requirements FAO/WHO nutrition meetings. Geneva: Food and Agriculture Organization/World Health Organization, 1985. Report series 724.

[9] FOOD AND DRUG ADMINISTRATION. Appendix B of the nutrition labeling regulations. Federal Register, Washington, v. 58, n. 3, p. 2193-2195, 6 6 $^{\text {th }}$, Jan. 1993.

[10] FRITSCH, C.W.; GALE, J.A. Hexanal as a measure of rancidity in low fat foods. Journal of the American Oil Chemists Society, v. 54, n. 6, p. 225-228, 1977.

[11] GALLIARD, T. Rancidity in cereal products. In: ALLEN, J.C.; HAMILTON, R.J. Rancidity in foods. London: Applied Science, 1983. 199p. Chapter 7: p.109-130.

[12] GRACZA, R. Aging and storage studies in flours and airclassified flour fractions. Cereal Chemistry, v. 42, n. 4, p. 333-358, 1965.
[13] HENLEY, E.C.; KUSTER, J.M. Protein quality evaluation by protein digestibility correlected amino acid scoring. Food Technology, v. 48, n. 4, p. 74-77, 1994.

[14] HWANG, P.; BUSHUK, W. Some changes in the endosperm proteins during sprouting of wheat. Cereal Chemistry, v. 50, p. 147-160, 1973.

[15] JOHNSON, A.H.; GREEN, J. Wheat and flours studies XVIII. A study of the nature of the acid responsible for the increase in acidity which occurs in flours during storage. Cereal Chemistry, v. 8, n. 2, p. 134-145, 1931.

[16] KAKADE, M.L.; LIENER, I.F. Determination of available lysine in protein. Analytical Biochemistry, v. 27, p. 273280, 1969.

[17] KUMAR, A.; CHAUHAN, B.M. Chemical composition and utilization of pearl millet sprouts. Nahrung, v. 37, n. 4, p. 356-363, 1993.

[18] LARSSON, M.; SANDBERG, A.-S. Malting of oats in a pilotplant process. Effects of heat treatment, storage and soaking conditions on phytate reduction. Journal of Cereal Science, v. 21, p. 87-95, 1995.

[19] LIMA, G.J.M.M.; ZANOTTO, D.L.; PIENIZ, L.C. et al. O trigo na alimentação de suínos e aves. Comunicado técnico 221 - Embrapa Suínos e Aves (CNPSA). Concórdia-SC: maio/98, p. 1-2.

[20] LORENZ, K. Cereal sprouts: composition, nutritive value, food applications. Critical Reviews in Food Science and Nutrition. V. 13, n. 4, p. 353-385, 1980.

[21] MILADI, S.; HEGSTED, D.M.; SAUNDERS, R.M. et al. The relative nutritive value, amino acid content, and digestibility of the proteins of wheat mill fractions. Cereal Chemistry, v. 49, n. 1, p. 119-127, 1972.

[22] MIRANDA, M., EL-DASH, A.A. Farinha integral de trigo germinado. 1. Caracterização química. In: CONGRESSO BRASILEIRO DE CIÊNCIA E TECNOLOGIA DE ALIMENTOS, XVI, 1998, Rio de Janeiro. Anais, Rio de Janeiro, v. 2, p. 1297-1300, 1998a.

[23] MIRANDA, M., EL-DASH, A.A. Farinha integral de trigo germinado. 2. Propriedades fisicas e funcionais. In: CONGRESSO BRASILEIRO DE CIÊNCIA E TECNOLOGIA DE ALIMENTOS, XVI, 1998, Rio de Janeiro. Anais, Rio de Janeiro, v. 3, p. 2063-2066, 1998b.

[24] MOLTEBERG, E.L.; VOGT, G.; NILSSON, A.; FROLICH, W. Effects of storage and heat processing on the content and composition of free fatty acids in oats. Cereal Chemistry, v. 72, n. 1, p. 888-93, 1995.

[25] NARA, A.B.W.; NAZÁRIO, G.; ALMEIDA, M.E.W. et al. (Coord.) Normas analíticas do Instituto Adolfo Lutz. 2 ed. São Paulo: Instituto Adolfo Lutz, 1976. v. 1: Métodos químicos e físicos para análise de alimentos. 371p.

[26] PETZKE, K.J.; EZEAGU, I.E.; PROLL, J. et al. Amino acid composition, available lysine content and in vitro protein digestibility of selected tropical crop seeds. Plant Foods for Human Nutrition, v. 50, n. 2, p. 151-162, 1997.

[27] PIENIZ, L.C.; ZANOTTO, D.L.; GUIDONI, A.L. et al. Trigo em substituição ao milho em rações para frangos de corte. In: Anais da XVIII Reunião da Sociedade Brasileira de Zootecnia. Fortaleza-CE: 21 a 26 de julho de 1996.

[28] SAS INSTITUTE INCORPORATION (Cary, NC, USA). The SAS for windows, release 6.08. Cary, 1992.

[29] SHARP, P.F. Wheat and flour studies. II. Aging. I. The change in hidrogen-ion concentration of wheat and mill products with age. Cereal Chemistry, v. 1, n. 3, p. 117-132, 1924.

[30] TKACHUK, R. Free amino acid in germinated wheat. Journal of the Science of Food and Agriculture, v. 30, n. 1, p. 53-58, 1979. 
[31] TAVERNER, M.R.; FARRELL, D.J. Availability to pigs of amino acids in cereal grains. 3. A comparison of ileal availability values with faecal, chemical and enzymic estimates. British Journal of Nutrition, v. 46, n.1, p. 173-180, 1981a.

[32] TAVERNER, M.R.; FARRELL, D.J. Availability to pigs of amino acids in cereal grains. 4. Factors influencing the availability of amino acids and energy in grains. British Journal of Nutrition, v. 46, n. 1, p. 181-192, 1981b.

[33] WOLZAK, A.; BRESSANI, R.; BRENES, R.G. A comparison of in vivo and in vitro estimates of protein digestibility of native and thermally processed vegetable proteins. Plant Foods for Human Nutrition, v. 31, n. 1, p. 31-43, 1981.

\section{6 - AGRADECIMENTOS}

Os autores agradecem ao CNPq e à FAPESP pelo apoio financeiro, à EMBRAPA Sementes Básicas, de Passo Fundo-RS, pela doação de trigo e à Rosa Maria Cerdeira de Barros, da FCF-USP, pela colaboração nas análises de aminoácidos. 